\title{
НЕКОТОРЫЕ АСПЕКТЫ ЭТИОЛОГИИ И ПАТОГЕНЕЗА СРК
}

\author{
Бийарсланова Зулгужат Шапиевна \\ студент \\ ФГБОУ ВО ДГМУ
}

\begin{abstract}
Аннотация: СРК не является психиатрическим или психологическим расстройством. Однако психологические факторы могут играть существенную роль в развитии симптомов и влиять на их тяжесть, а, следовательно, значительно ухудшать качество жизни, побуждая пациентов часто обращаться за медицинской помощью. Ключевым механизмом развития боли при этом заболевании является повышенная чувствительность рецепторов толстой кишки к растяжению. Болевой сигнал передается в головной мозг, что в свою очередь может вызывать стимуляцию кишечника, усиливая его моторику и боль в животе, нарушая частоту и консистенцию стула, а это значительно портит качество жизни человека и проявляется в виде депрессии, ипохондрии.

Ключевые слова: СРК (синдром раздраженного кишечника), висцеральная гиперчувствительность, диарея, еда, стул, ПБС (плотные белковые соединения),зонулин, окклудин, мозговая активность.
\end{abstract}

\section{SOME ASPECTS OF THE ETIOLOGY AND PATHOGENESIS OF IBS}

\section{Biyarslanova Zulguzhat Shapievna}

student

FGBOU DSMU

\begin{abstract}
IBS is not a psychiatric or psychological disorder. However, psychological factors can play a significant role in the development of symptoms and affect their severity, and therefore significantly worsen the quality of life, prompting patients to often seek medical help. The key mechanism of pain development in this disease is an increased sensitivity of the colon receptors to stretching. The pain signal is transmitted to the brain, which in turn can cause intestinal stimulation, increasing its motility and abdominal pain, disrupting the frequency and consistency of stool, and this significantly spoils the quality of human life and manifests itself in the form of depression, hypochondria.
\end{abstract}


Key words: IBS (irritable bowel syndrome), visceral hypersensitivity, diarrhea, food, stool, PBS (dense protein compounds), zonulin, occludin, brain activity

СРК определяется как функциональное расстройство кишечника, проявляющееся рецидивирующими болями в животе, которые возникают, по меньшей мере, 1 раз в неделю и связаные с дефекацией, а также с изменением частоты и формы (внешнего вида) стула.

СРК не является психиатрическим или психологическим расстройством. Однако психологические факторы могут играть существенную роль в развитии симптомов и влиять на их тяжесть, а следовательно, значительно ухудшать качество жизни, побуждая пациентов часто обращаться за медицинской помощью. К наиболее часто встречаемым психологическим нарушениям при СРК относятся тревожные состояния, депрессия, соматизация, ипохондрия, навязчивые состояния и страхи.

1. СРК - это заболевание, при котором не находят органических изменений

2. СРК - в 73-90\% случаев начинается без какой-либо причины

3. СРК - протекает со спонтанными ремиссиями

4. СРК - при длительном течении не приводит к тяжелым последствиям

5. СРК - часто сочетается с симптомами в других системах (дыхательной, урогенетальной, вестибулярной и пр.)

6. СРК - симптомы часто возникают после перенесенного инфекционного или воспалительного заболевания

7. СРК - эффективно купируется психотропной терапией

В настоящее время нет четкого представления о точных причинах возникновения СРК. Предполагается роль психоэмоционального фактора (острый и хронический стресс, тревожные состояния, депрессия), наследственной предрасположенности (выявлены несколько генов, ассоциированных с СРК), перенесенной кишечной инфекции или воспалительного заболевания кишечника. Известно, что у пациентов с СРК нередко выявляются признаки слабо выраженного воспаления в слизистой оболочке толстой кишки и повышенная активность некоторых клеток, продуцирующих активные вещества (например, серотонин).

Несмотря на отсутствия понимания точной причины возникновения СРК, медицинской науке известен ключевой механизм развития боли при этом 
заболевании - повышенная чувствительность рецепторов толстой кишки к растяжению. В норме в толстой кишке постоянно происходит стимуляция чувствительных нервных окончаний, однако эти воздействия не приводят к развитию неприятных симптомов. У больных СРК даже нормальный уровень растяжения толстой кишки газами и каловыми массами вызывает появление боли. Болевой сигнал передается в центральную нервную систему (головной мозг), что в свою очередь может вызывать стимуляцию кишечника, усиливая его моторику и боль в животе, нарушая частоту и консистенцию стула. Лица, длительно находящиеся в состоянии стресса или тревоги, имеют повышенное восприятие чувства боли, у них долгое время сохраняется «память» о болевых ощущениях. Длительное «раздражение» головного мозга сигналами из толстой кишки может привести к появлению жалоб, совсем не связанных с кишечником.

\section{Критериями позитивного диагноза являются:}

1. Острый дебют

2. Вариативность симптоматики и течения (кратковременное облегчение после любого типа лечения, с последующим облегчением)

3. Ассоциированные симптомы (головная боль, головокружения, дыхательные расстройства, панические аттаки)

4. Профилактический прием препаратов (спазмолитики, обезболивающие, антидиарейные)

5. Множество обследований, включая инвазивные (3-5 раз в год колоноскопий и гастроскопий)

6. Ограничительное поведение (когда больные приспосабливаются к симптомам, которые им мешают жить)

- Прием больших доз противодиарейных препаратов ( до 100 таблеток в месяц)

- Профилактический прием препаратов

- Отказ от еды за день до предстоящей поездки

- Зависимость жизни от наличия туалетов и особенностей питания

- Ограничение профессиональной карьеры

7. Связь дебюта и обострений с психогенными факторами (конфликтные ситуации, конкретные страхи, суммарный стресс)

8. Детская травма

9. Тревожная мнительность 


\section{0. Эффективность психотропной терапии (психотерапия +} психофармакотерпия)

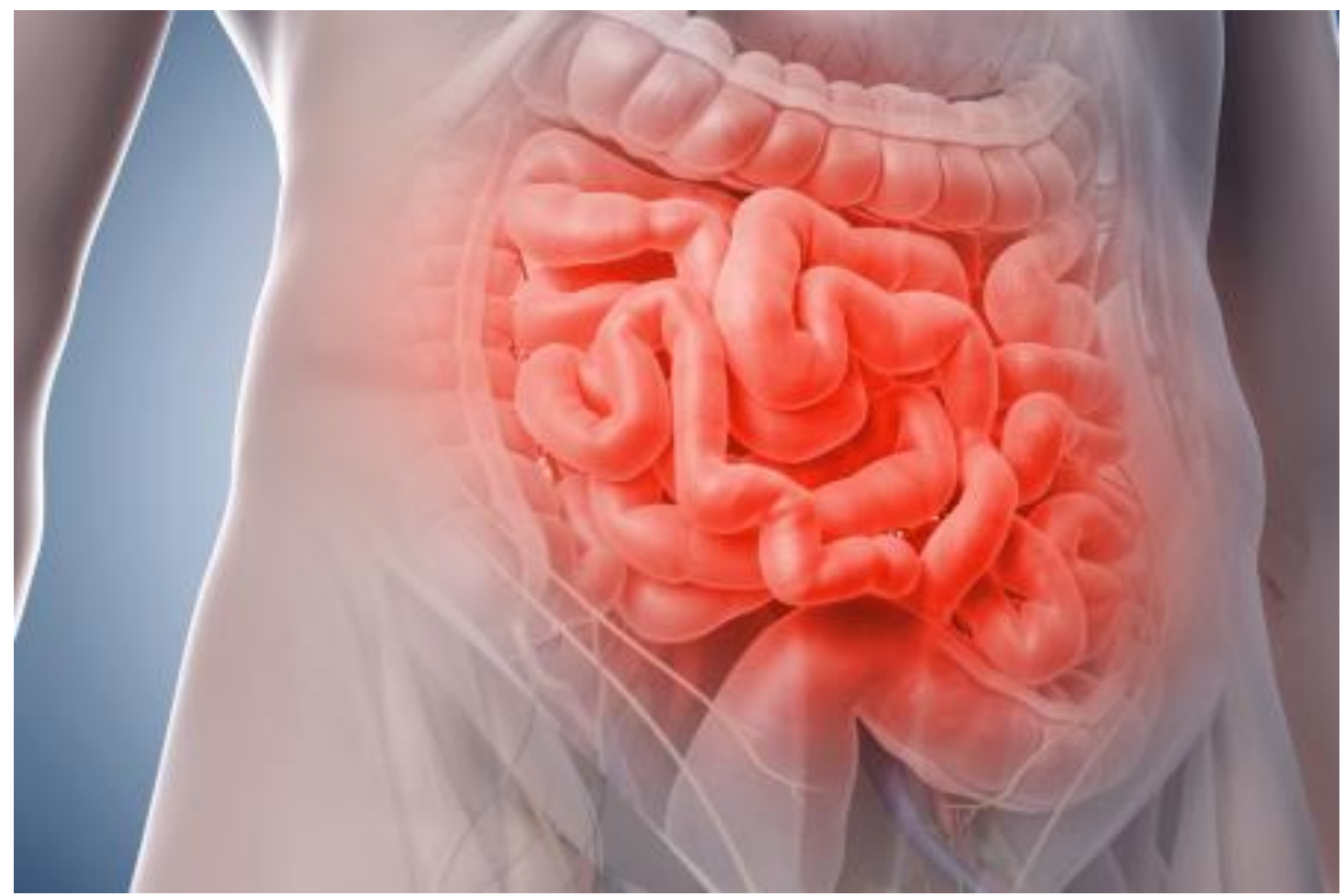

СРК имеет определенную симптоматику - «ABCD» синдрома раздраженной кишки (The ABCDs of irritable bowel syndrome):

A - боль в животе или дискомфорт, обычно в нижней части живота, но может быть без четкой локализации по всему животу (Abdominal pain or discomfort).

В - вздутие живота или ощущение распирания (Bloating or visible distention).

$\mathrm{C}$ - запор: затрудненная эвакуация при дефекации или редкая дефекация (Constipation: hard, difficult-to-evacuate, or infrequent stools).

D - диарея: кашицеобразный, водянистый или частый стул (Diarrhea: loose, watery, or frequent stools).

Экстракишечные симптомы, такие как усталость, головная боль, боли в спине, боль в мышцах, нарушения сна (Extra-bowel symptoms such as fatigue, headache, backache, muscle pain, and sleep disturbance).

При постановке диагноза необходимо уточнить вопросы, касаемые диареи и питания, а именно:

- Частота и консистенция диареи 


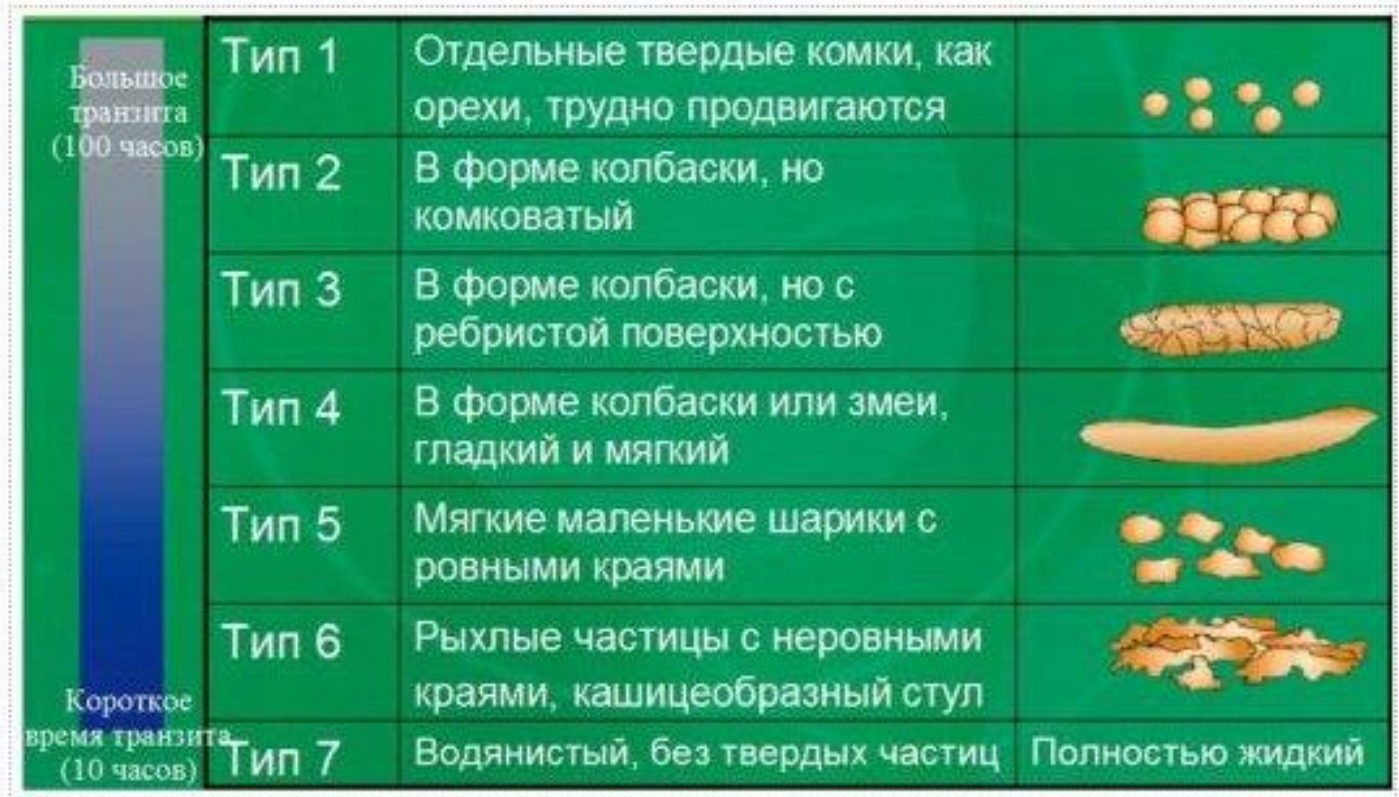

Бристольская шкала формы кала

- Наличие ассоциированных болей (тошнота, урчание, потливость, боль в разных частях тела, вздутие, озноб, головокружение)

- Латенция от позыва до стула

- Боль, спазм перед стулом

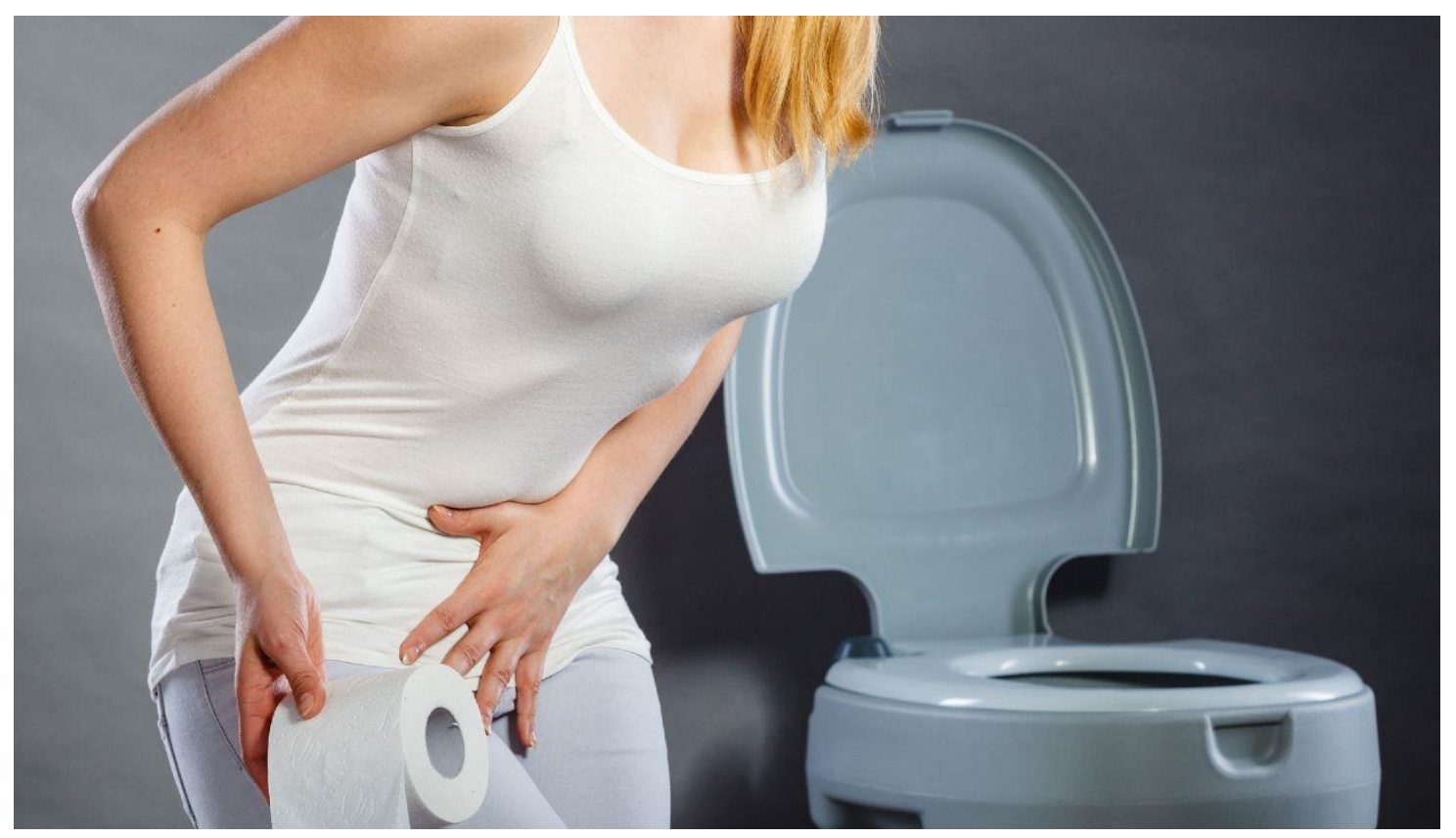

- Эпизоды упускания кала 
- Распределение по времени и ситуациям ( утро, вечер, ночь, отпуск, выходные дни)

- Связь с характером и временем еды, лекарствами, наличие туалета

- Характер еды (клетчатка, жареное, острое)

- Свежесть еды (сомнительные продукты) и место его приготовления

У пациентов СРК ведущим симптомом является боль в животе, которая формируется в результате нарушения взаимодействие между кишечником и мозгом, что приводит к изменению регуляции моторной функции кишечника и развитию висцеральной гиперчувствительности (ВГЧ).

\section{Патогенез висцеральной гиперчувствительности}

Ноцицепторы кишечника, воспринимают болевые стимулы и проецируют сигналы на ноцицептивные нейроны спинного мозга, которые передают информацию в супраспинальные центры. Этот сигнал достигает подкорковых и корковых структур головного мозга, которые в совокупности кодируют афферентную информацию и генерируют эфферентный сигнал к периферии. Таким образом, нисходящие пути модулируют нейронную активность оказывающую либо тормозящее, либо облегчающее влияние на ощущение боли. Хроническая активация ноцицепторов вследствие хронического высвобождения медиаторов воспаления (серотонин, ацетилхолин, гистамин, простогландин 2 и др) приводит к сенсибилизации рецепторов и непредсказуемым приступам висцеральной боли)

Было проведено исследование, куда были включено 28 пациентов СРК и 19 здоровых пациентов. Церебральная функция была оценена с помощью МРТ. Во время визуализации латексный баллончик был помещен в прямую кишку примерно на 10 см от заднего прохода, после чего нагнетался воздух. Изображения были получены при расширении кишки на 40 мл, 80 мл и 120 мл.

В итоге были получены результаты:

Мозговая активность выявлена в теменных областях, префронтальная кора, мозжечок, передняя поясная извилина, островковая кора и таламус и увеличивалась вместе с увеличением дилатации прямой кишки.

Выводы:

Результаты указывают на то, что изменения в активации мозга прямо связано с изменениями в растяжении прямой кишки баллоном 


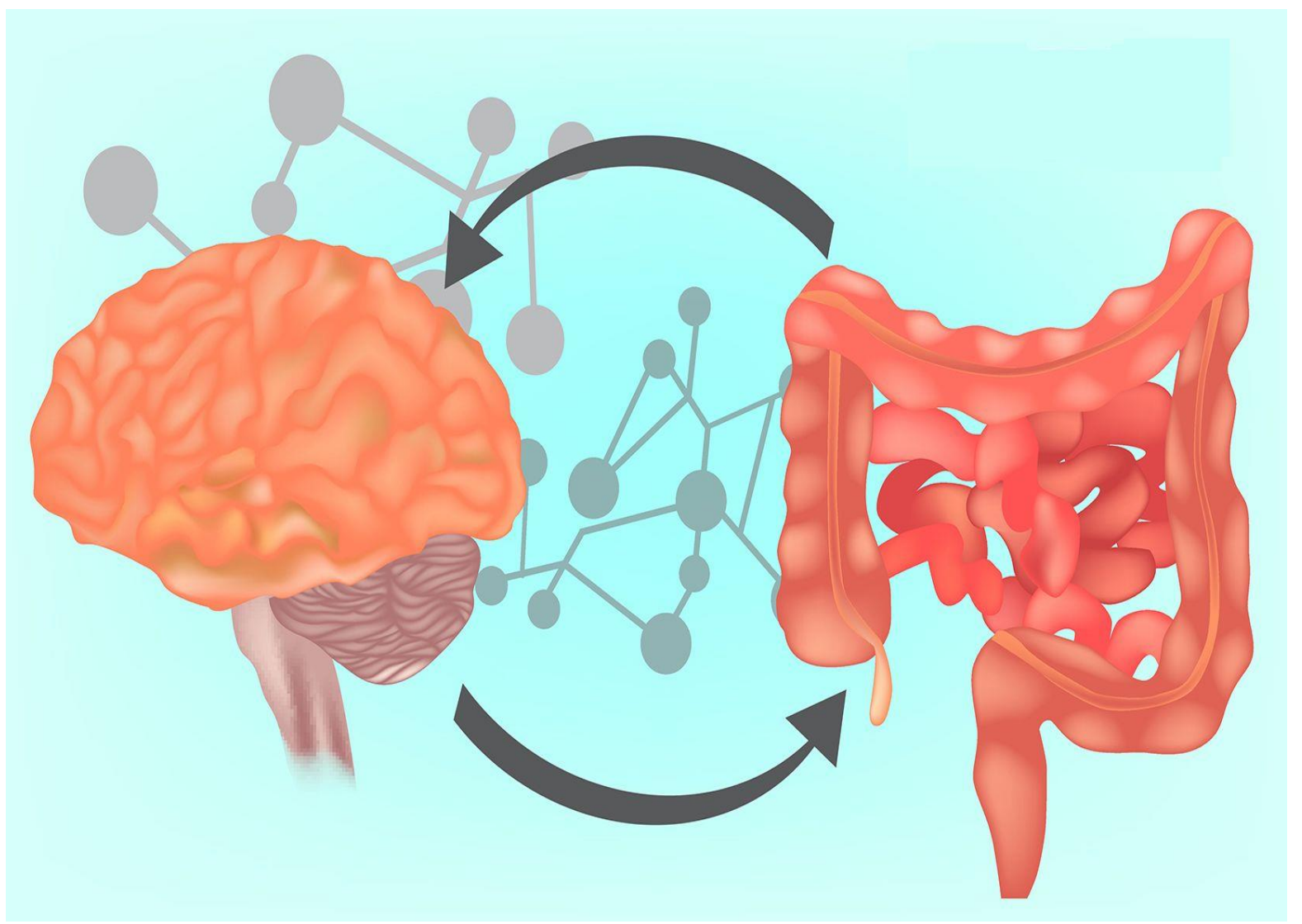

Важным звеном нормальной барьерной функции толстой кишки являются:

1. Структура и эпителиальная активность в однослойном плазматическом эпителии среди энтероцитов множество бокаловидных клеток, обильно секретирующих слизь.

2. Макро- микроструктуры собственной пластинки эпителиального слоямного кровеносных и лимфатических сосудов, множество нервных сплетений;

3. Особенности локальной иммунной системы - большое количество лимфоцитов, плазмоцитов, макрофагов, гранулоцитов и большое скопление лимфоидной ткани

4. У здоровых людей локальные иммунные реакции являются определяющим фактором в ограничении всасывания токсических и бактериальных антигенов, так как локально происходит выработка большого количества лизоцими и секреторного иммуноглобулина А, позволяющих удалять постоянного образующиеся иммунные комплексы. 


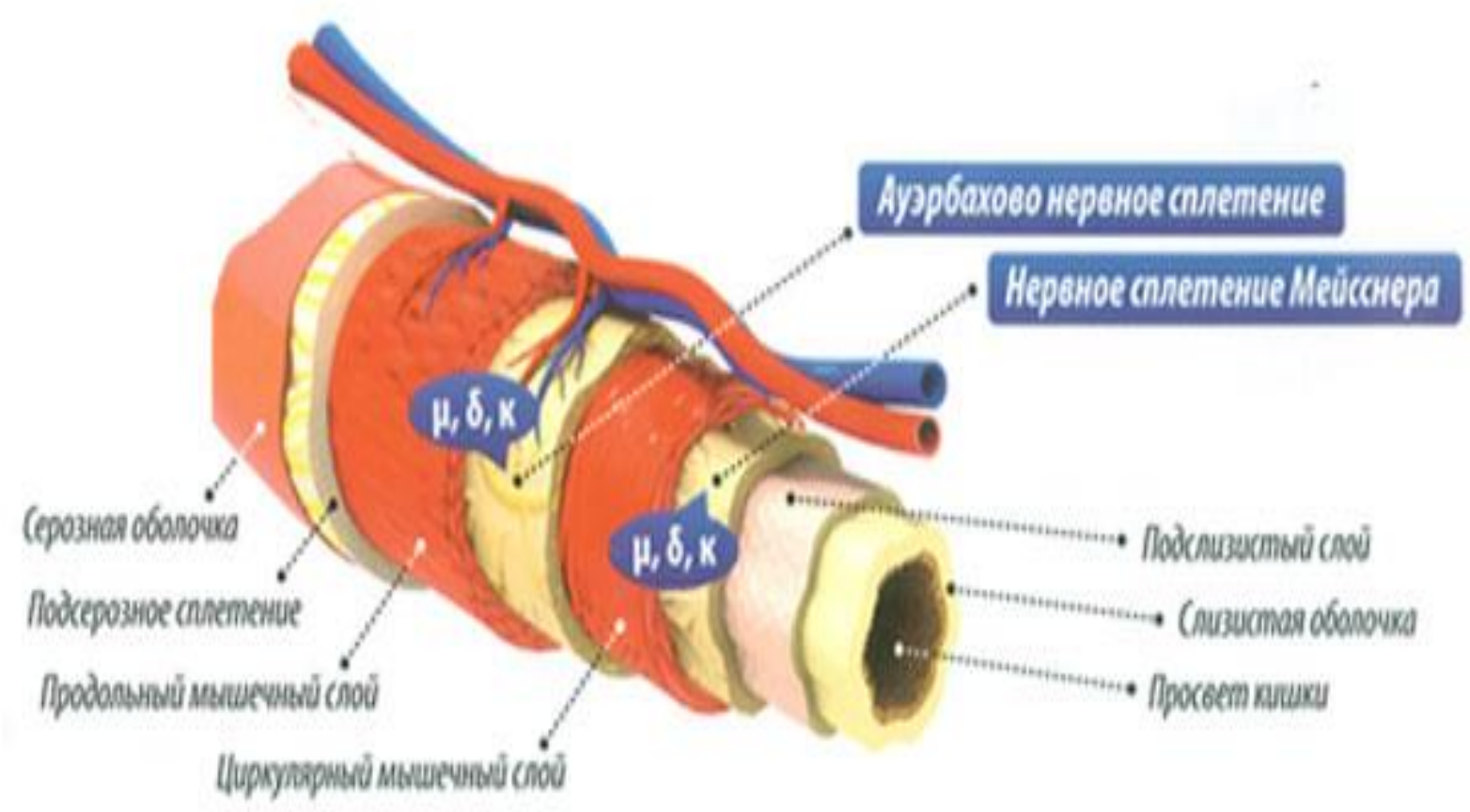

У пациентов с функциональными заболеваниями выявлены изменения межклеточных плотных контактов, степень которых определяет развитие заболевания

- Кишечная проницаемость зависит от «плотных белковых соединений» (ПБС)

- ПБС - самый важный компонент конструкции плотных контактов клеток эпителия в барьерной функции кишки;

- ПБС, являясь каркасами для белкового комплекса окклудина, актина, клаудина и кадхерина, связывается с цитоскелетом через зонулин;

- ПБС регулирует проницаемость барьера, способны плотно герметизировать соединения между клетками, удерживая белковые молекулы в билипидном слое и обеспечивая направленный транспорт.

- Регулирует и устраняет соединения между клетками эпителия. В регуляции экспрессии и локализации белков плотных контактов важны кишечные бактерии и диетические компоненты, которые ослабляют барьерную функцию эпителиальных клеток.

Плотные контакты включают около 200 аминокислот, соединения которых определяют защиту организма от воздействий. Среди плотных контактов выделены группы: 
1. Плотные белковые соединения (ПБС) плотные контакты: между латеральными мембранами эпителиальных клеток включают интеральные белки с элементами цитоскелета:

- Окклудин, клаудин-1, Е-кадхерин, зонулин-1, зонулин-2, катенины, актин, цингулин;

- Окклудин и зонулины действуют как каркасы для других белков и вхаимодействуют с актиновой сетью, устраняя соединения между клетками;

- ПБК разрушается при низком содержании кальция

- Клаудины поддерживают водный барьер

- ПБС разрушается при взаимодействии зонулина с актином

2. Адгезивные соединения

3. Щелевые соединения

4. Десмосомы

Белки плотных соединения являются высокочувствительными и селективными, открываясь и закрываясь в ответ на воспалительные и регуляторные цитокины, ограничивая поступление антигенов во внутреннюю среду организма

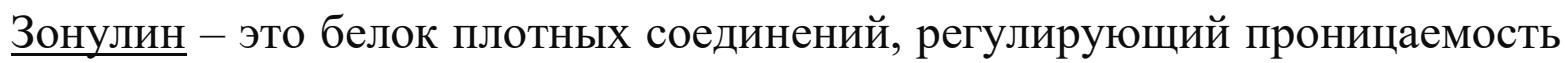
кишечного барьера, изменяющийся в ответ на антигенные стимулы, вырабатывается в эпителиоцитах слизистой кишки. Зонулин, связываясь с рецепторами плотных белковых соединений, сокращает клеточный скелет клеток эпителия, открывают зоны между эпителиальными клетками для выхода веществ, повышают проницаемость стенки кишки. Зонулин - это лабораторный маркер, показывающий состояние нарушенного кишечного барьера. При этом для правильной работы всего организма этот барьер должен быть устойчивым

\section{Методы оценки проницаемости кишки}

- Определение соотношения сахаров: лактулозы и маннита с оценкой абсорбции обоих сахаров по содержанию сахаров в моче

- Определение в сыворотке крови белка куриного яйца после пероральной нагрузки

Методика исследования: у пациента натощак ( через 12 часов после приема пищи) и через 3 часа после нагрузки белком двух куриных яиц в сыворотке крови иммуноферментным методом определяют концентрацию белка куриного яйца. Норма $=4$ нг/мл. У больных $\mathrm{c}$ повышенной 
проницаемостью слизистой оболочки тонкой кишки концентрация белка увеличивается в несколько раз.

При патологии кишечника нарушаются межэпителиальные контакты слизистой кишки, происходит транслокация бактерий и энтеротоксина липополисахарида(ЛПС). ЛПС грамотрицательных бактерий: активирует продукцию провоспалительных цитокинов NO-синтазу и NADPH-оксидазу и факторы, формирующие стресс в нервной системе; активирует микроглию и разрушает гематоэнцефалический барьер, разрушаются патофизиологические события. Здоровая микробиота производит нейроактивные медиаторы (серотонин, бутират и др.) которые помогают сохранить кишечный барьер. У пациентов в ряде исследований выявлено повышение уровня серотонина в энтерохромаффинных клетках (ЭК) кишечника по сравнению со здоровыми людьми. Результаты биопсии у всех пациентов были в пределах нормы с использованием обычных критериев, однако количественное исследование показало увеличение ЭК клеток $(p=0,017)$ по сравнению с контрольной группой $(p=0,02)$. Также было увеличено количество Т-лимфоцитов собственной пластинки слизистой оболочки $(p=0,026)$ и количество тучных клеток $(\mathrm{p}=0,054)$ по сравнению с контрольной группой [24]. Увеличение на $25 \%$ в ректальной зоне числа ЭК клеток может привести к увеличению уровня серотонина и к последующей диарее.

В настоящее время очевидно, что СРК - это не одно заболевание, а четко выявляемый симптомокомплекс, который сочетает симптомы различных базовых физиологических детерминант «от кишечника к мозгу и обратно». Таким образом, одна «волшебная таблетка» в качестве лечения этого расстройства вряд ли применима: лечение должно основываться на моно- или полинаправленном фармакологическом воздействии, для целевой коррекции физиологической, индивидуальной для каждого человека. 


\section{Список литературы}

1. Жуков Н.А. и соавт. Современные представления о патогенезе синдрома раздраженного кишечника // Клиническая медицина. - 2003. - № 12. C. 7-12.

2. Костенко М. Б., Ливзан М.А. Механизмы развития синдрома раздраженного кишечника // Сибирский журнал гастроэнтерологии и гепатологии. - 2000. -№ 10. - С. 32-35.

3. Парфенов А.И., Ручкина И.Н., Атуллаханов Р.И. и др. Постинфекционный синдром раздраженной кишки. Терапевтический архив, 2009, 81 (2): 39-45

4. Генетические основы синдрома раздраженного кишечника. МКНЦ им. А. С. Логинова

5. Longstreth G.F., Thompson W.G., Chey W.D. et al. Functional bowel disorders // Gastroenterology. 2006. Vol. 130. P. 1480-1491.

6. Spiller R., Garsed K. Infection, inflammation, and the irritable bowel syndrome // Digestive and Liver Disease. 2009. Vol. 41. P. 844-849.

7. Thompson W.G., Longstreth G.F., Drossman D.A. et al. Functional bowel disorders and functional abdominal pain // Gut. 1999. Vol. 45(suppl 2):II43-47.

8. Clouse R.E., Mayer E.A., Aziz Q. et al. Functional abdominal pain syndrome // Gastroenterology. 2006. Vol. 130. P. 1492-1497.

(C) 3.Ш. Бийарсланова, 2021 